\title{
The Medical Therapy of Angina Pectoris
}

\author{
Daniel D. Van Hamersveld, M.D. and James R. Stewart, M.D.
}

Since the first published observations of occluded coronary arteries by Morgagni in 1761, and the classic description of angina pectoris by William Heberden, as presented to the Royal College of physicians in $1768,{ }^{2}$ the medical treatment of angina has demonstrated a surprising lack of diversity. Heberden was able to effect temporary relief with opiates, but noted no beneficial response to wine, spirits, or bloodletting. ${ }^{3}$ In 1867 , nitrates were first used specifically for angina, in the form of amyl nitrite, by Thomas Lauder Brunton, ${ }^{4}$ thus initiating the form of pharmacologic intervention that has persisted as the major form of therapy to the present day.

Angina pectoris is the discomfort that occurs as a manifestation of myocardial ischemia. The typical characteristics include: (1) location over the sternum or very near it; (2) radiation to the jaw, left shoulder, or arm; (3) a feeling of pressure, burning, or tightness; (4) precipitation by exertion, cold, or emotional distress; (5) duration of 30 seconds to 30 minutes; and (6) relief in 45 seconds to 5 minutes following the use of nitroglycerin.

The clinical syndrome of angina pectoris is not a diagnostic endpoint, however, since several cardiac disorders other than atherosclerotic cardiovascular disease are well-known to incorporate symptoms of angina. Important examples of these included aortic stenosis or regurgitation, hypertrophic cardiomyopathy (IHSS), and reversible coronary vasospasm (Prinzmetal's angina).

Angina is classified as either stable or unstable, although the medical therapy of the former will be the major focus of this review. Unstable angina (also known as pre-infarction or crescendo angina) is typified by the presence of angina pectoris involving at least one of the following patterns: (1) angina of new onset, brought on by minimal exertion; (2) the development of more severe, prolonged, or frequent angina occurring in the

Address for reprints: James R. Stewart, M.D., Division of Cardiovascular Diseases, William Beaumont Hospital, Royal Oak, MI 48072.
From the Department of Internal Medicine, Division of Cardiology,

University of Michigan Medical School, Ann Arbor, Michigan

setting of stable, exertional angina; and (3) angina at rest as well as with minimal exertion. ${ }^{5}$

\section{Medical Treatment}

The medical treatment of angina pectoris involves three general categories: (1) minimizing specific risk factors for coronary artery disease (CAD), (2) adjustment of the patient's life style, and (3) various pharmacologic interventions. Two of the most important, and also controllable, risk factors for coronary artery disease are smoking and hypertension. The Framingham study has demonstrated an increased risk of developing CAD from smoking, ${ }^{6}$ and other studies have shown that discontinuing cigarette use is associated with a decrease in the incidence of myocardial infarction. ${ }^{7}$ The control of moderate to severe hypertension is also associated with decreased cardiovascular mortality, but the effect of treating mild hypertension is less well-delineated in terms of risk for CAD. ${ }^{8}$ Similarly, the effects of lowering an elevated blood cholesterol, or further lowering a normal cholesterol, are not definitely known at this time. ${ }^{9}$ However, it is reasonable to recommend a diet that maintains ideal body weight, increases the ratio of unsaturated to saturated fats, and avoids cholesterol-rich foods. This is also important in view of the fact that serum high-density lipoproteins (HDL) recently have been shown to have an inverse relationship to the development of ischemic heart disease, ${ }^{10-12}$ and that blood levels of HDL can be increased by the previously mentioned dietary regimen, by regular dynamic exercise, and by the ingestion of alcohol in moderate amounts.

A physical training program in the form of regular exercise (swimming, jogging, walking, bicycling, etc) is also beneficial because of the concomitant improvement 
in cardiac performance, ${ }^{13}$ which allows given work loads to be accomplished at lower blood pressures and heart rates, thus reducing myocardial oxygen demands and prolonging the duration of exercise in many cases. Other possible benefits include an overall sense of well-being and greater compliance with other recommended alterations in life style.

The pharmacologic treatment of stable angina pectoris involves several classes of drugs, including nitrates, beta-adrenergic blocking agents, diuretics, digitalis, anticoagulants, and anti-arrhythmics. The rationale for the use of most of these medicines in the therapy of ischemic heart disease is their respective hemodynamic alterations, which tend to reduce myocardial oxygen demands. The four major determinants of myocardial oxygen demand are: (1) heart rate; (2) systolic blood pressure [afterload]; (3) left ventricular volume [preload]; and (4) the speed of the left ventricular pressure rise [contractility]. ${ }^{14}$ Also, since coronary blood flow occurs essentially only during diastole, coronary perfusion pressure (mean arterial pressure minus left ventricular end-diastolic pressure) can be increased by causing changes that decrease pre-load (LVEDP).

\section{The Nitrates}

The major class of anti-anginal drugs is the nitrates, including nitroglycerin and isosorbide dinitrate. The major beneficial hemodynamic effects include: (1) reduction of preload via venous dilatation, (2) a smaller decrease in afterload via effects on peripheral resistance, (3) dilatation of the large epicardial coronary arteries, (4) improved collateral myocardial blood flow, and (5) increased ventricular compliance.

The drug of choice for acute anginal attacks remains sublingual nitroglycerin. Its onset of action can be as short as 45 seconds, with maximum effect within 3 to 5 minutes. Various strengths are available, but the usual dose is $0.3 \mathrm{mg}$ (1/200 grain) or $0.4 \mathrm{mg}(1 / 150$ grain). Besides its usefulness for relieving angina episodes, it also can be administered prophylactically, prior to anticipated situations or levels of exercise that are likely to result in angina. Patients should be advised that, despite evidence indicating some degree of tolerance to the circulatory effects of nitrates used chronically and some cross tolerance to sublingual nitroglycerin with the concurrent use of long acting nitrates, ${ }^{15}$ the anti-anginal effect should be predictable and persistent regardless of the frequency or duration of its use. In addition, the lack of significant improvement in anginal symptoms in someone with stable angina using one to two sublingual nitroglycerin tablets every 3 to 5 minutes, should, after 10 to 15 minutes, suggest more severe ischemia or actual infarction, and medical attention should be sought immediately.
The other two major forms of nitrates used clinically are long-acting, and include nitroglycerin ointment and isosorbide dinitrate. These have only recently come into widespread use because of controversy regarding their efficacy, especially that of the oral preparations. Until the middle of the past decade, they were believed to be inadequate because of unreliable gastrointestinal absorption and rapid hepatic metabolism. However, one of the difficulties with studies done until that time was the use of insufficient doses of nitrates to overcome these problems. ${ }^{16}$

For example while using doses of isosorbide dinitrate in the range of 15 to $60 \mathrm{mg}$ orally in patients with stable angina, it has been shown that the effects of reduced systolic blood pressure and increased duration of exercise before angina last for up to eight hours after a single dose. ${ }^{17}$ The recommended dosing schedule for oral isosorbide dinitrate is from 5 to $40 \mathrm{mg}$ on a qid basis, ${ }^{18}$ and its baseline dose can be titrated to an endpoint of either control of angina, hypotension, or intractable headaches.

Two percent nitroglycerin ointment is also an effective long-acting nitrate when applied to skin surfaces. Studies have shown a significant decrease in LVEDP (left ventricular end-diastolic pressure) and systolic arterial pressure lasting at least 1 hour after a dose, ${ }^{19}$ and improved exercise tolerance has been documented at 3 to 4 hours. ${ }^{20}$ The recommended dosing schedule for nitroglycerin ointment is 0.5 to 2 inches every 4 hours, ${ }^{18}$ with titration to the same endpoint as for isosorbide dinitrate.

\section{Blocking Agents}

The next major class of anti-anginal drugs is the betaadrenergic receptor blockers, of which propranolol and nadolol are currently available in the United States (metoprolol, a "cardio-selective" beta ${ }^{1}$ receptor blocker, is not yet specifically recommended by the FDA for use in ischemic heart disease). The beneficial effects of beta blockers in ischemic heart disease are related to decreased myocardial oxygen requirements by the following actions: (1) reduction of heart rate, (2) reduction of contractility, and (3) a decrease in arterial blood pressure. The increase in left ventricular end-diastolic volume that can occur and thus increase oxygen demands, is usually offset by these actions.

Side effects that may obviate or modify the use of these drugs include excessive bradycardia, fatigue, postural hypotension, weakness, hallucinations, poor coordination, depression, heart failure, broncho-constriction, and diarrhea. Therefore, in patients having either a history of chronic lung disease with a bronchospastic component or a history of overt congestive heart failure, beta blockers probably should be avoided. 
Studies have documented significantly improved exercise tolerance and reduction in anginal episodes occurring for periods up to 8 to 12 hours after a single dose of propranolol. ${ }^{21}$

On occasion, digitalis can be added to propranolol when left ventricular enlargement is present at rest or when left ventricular dysfunction occurs during exercise, thus preventing overt heart failure and improving exercise tolerance. ${ }^{22}$

The dosage of propranolol averages 80 to $320 \mathrm{mg}$ per day in divided doses ( 2 to 4 doses, usually), with the endpoint being either control of angina, heart rate less than 60 at rest, and less than 20-beat increase with modest exercise, or the development of intolerable side effects.

On the basis of the pharmacologic actions of these drugs, as well as considerable clinical experience, the medical management of patients with stable angina pectoris should include sublingual nitroglycerin as the basic drug, and possibly as the only drug if anginal episodes are rare and predictable. However, if angina is occurring on a weekly basis, long-acting nitrates or beta blockers should be added, either separately or in combination. Should it not be possible to reach the goal of a satisfactory life style for the patient in the face of infrequent or more regular but predictable and stable episodes of angina while on a maximal anti-anginal program, then alternatives, such as cardiac catheterization with a view toward coronary artery bypass grafting, must be considered.

Other drugs also may play a role in the treatment of angina. Diuretics can reduce pre-load (LVEDP) and thus decrease myocardial oxygen demands in the presence of left ventricular enlargement and increased LVEDP. Aspirin is being studied intensively because of its antiplatelet ${ }^{23}$ and prostaglandin synthetase inhibiting activity, ${ }^{24}$ as are other drugs with similar actions. A new class of drugs with anti-arrhythmic and anti-anginal properties known as calcium antagonists (inhibitors of the slow inward calcium current of myocardial cell membranes) is still under investigation in the United States, but some of these drugs already have demonstrated the ability to prolong exercise time and reduce the frequency of ischemic pain in stable angina pectoris. ${ }^{25}$

\section{Other Conditions}

Two other conditions involving myocardial ischemia should be mentioned briefly. The occurrence of unstable angina, as defined earlier, should be met with an aggressive approach, including admission to a hospital for close monitoring; maximal use of nitrates and beta blockers; narcotics, if necessary, for pain relief, and if pain relief has not been achieved, even intra-aortic balloon counterpulsation. Cardiac catheterization and possible coronary artery bypass surgery can be considered, although current evidence suggests no increased morbidity or mortality from stabilizing patients medically prior to bypass surgery. ${ }^{26}$

Prinzmetal's angina, or variant angina pectoris, has been recognized for over 20 years as a clinical entity, but firm documentation of reversible coronary vasospasm as its etiologic factor did not occur until 1973. ${ }^{27}$

The full syndrome includes chest pain of anginal quality at rest; an inconsistent relationship of the chest pain to exercise; frequent preservation of exercise tolerance; reversible ST segment elevation associated with pain; and, occasionally, ventricular arrhythmias and various degrees of A-V block. Approximately $50 \%$ of patients with variant angina have associated significant coronary artery disease; a somewhat smaller number have completely normal coronary arteriograms. The treatment for variant angina involves nitrates, since vasospasm usually responds promptly to nitroglycerin. Beta blockers, such as propranolol, should probably not be used unless there is significant underlying coronary artery disease and the patient responds favorably to a clinical trial. Blocking the vasodilating effect of beta 2 receptors in the coronary arteries potentially allows unopposed alpha-receptormediated vasoconstriction, thus exacerbating the syndrome. The use of calcium antagonists, such as verapamil and nifedipine, has been shown in several studies to effectively reduce the frequency of coronary vasospasm by as much as $90 \%$. The overall prognosis of variant angina in the absence of coronary artery disease is more favorable than with classic angina pectoris, despite the small incidence of sudden death. ${ }^{29}$

\section{Conclusions}

Stable angina pectoris secondary to arteriosclerotic cardiovascular disease is a common clinical entity, and a rational program of pharmacologic intervention is available and is often successful in controlling symptoms and maintaining desirable levels of physical activity for the patients. Despite an average annual mortality rate of $4 \%$ in persons with stable angina and $5 \%$ following a non-fatal myocardial infarction, ${ }^{30}$ the longevity following coronary artery bypass grafting has only been definitely improved in those with significant stenosis of the left main coronary artery, which occurs in less than $10 \%$ of patients with coronary artery disease.

The mainstay of treatment for stable angina pectoris should include the use of appropriate drugs in adequate amounts, the reduction of risk factors, and the appropriate alteration of life sytle. Coronary artery bypass grafting is a palliative but suitable adjunct when medical management fails to either control symptoms or allow the patient a sufficient level of activity to maintain a satisfactory quality of life. 


\section{Drug Names}

isosorbide dinitrate: Isordil, Sorbitrate, Sorate, Isotrate, Sorbide nitroglycerin: Nitrostat

nitroglycerin ointment: Nitro-Bid Ointment, Nitrogyn Ointment,

Nitrol Ointment

nadolol: Corgard

metoprolol: Lopressor

propranolol: Inderal

\section{Addendum}

Since this article was originally written the calcium channel blockers verapamil (Isoptin, Calan) and nifedipine (Procardia) have been released for use in angina pectoris. In addition, several additional $\beta$-adrenergic blockers have become available for use including metropolol (Lopressor), atenolol (Tenormin), and timolol (Blocadren).

\section{References}

1. Morgagni GB: The Seats and Causes of Diseases (1761), vol 1. London, Millar and Codell, 1769, pp 725-819

2. Heberden W: Some account of a disorder of the breast. Med Trans $\mathrm{R}$ Coll Physicians Lond 1:59, 1772

3. Lauder Brunton T: On the use of nitrite of amly in angina pectoris. Lancet ii:97, 1867

4. Braunwald E, Ed. Heart Disease: A Textbook of Cardiovascular Medicine. Philadelphia, WB Saunders, 1980

5. Gordon T, Sorlie P, Kannel WB: The Framingham Study. An Epidemiological Investigation of Cardiovascular Disease, Section 27. Washington, DC, US 1971

6. Gordon T, et al: Death and coronary attacks in men after giving up cigarette smoking. A report from the Framingham Study. Lancet ii: 1345,1974

7. Hypertension Detection and Follow-up Program Cooperative Group: The hypertension detection and follow-up program. Prev Med 5:207, 1976

8. Lipid Research Clinics Program: The coronary primary prevention trial: Design and implementation. J Chronic Dis 32:609, 1979

9. Rhoads GG, et al: Serum lipoproteins and coronary heart disease in a population study of Hawaii Japanese men. $N$ Engl J Med 294:293, 1976

10. Miller GJ, Miller NE: Plasma high-density lipoprotein concentration and development of ischaemic heart disease. Lancet $i: 16$, 1975

11. Gordon T, et al: High-density lipoprotein as a protective factor against coronary heart disease. The Framingham Study, Am I Med $62: 707,1977$
12. Clausen JP, Trap-Jensen J: Heart rate and arterial blood pressure during exercise in patients with angina pectoris: Effect of training and of nitroglycerin. Circulation 53:436, 1976

13. Robinson BF: The mode of action of beta antagonists in angina pectoris. Postgrad Med J 47 (suppl 2):41, 1971

14. Thadani $U$, et al: Tolerance to the circulatory effects of oral isosorbide dinitrate: Rate of development and cross-tolerance to glyceryl trinitrate. Circulation 61:526, 1980

15. Goldstein RE, et al: Clinical and circulatory effects of isosorbide dinitrate: Comparison with nitroglycerin. Circulation 43:629, 1971

16. Thadani $U$, et al: Oral Isosorbide Dinitrate in the treatment of angina pectoris; dose-response relationship and duration of action during acute therapy. Circulation 62:491, 1980

17. Braunwald E, Ed. Heart Disease: A Textbook of Cardiovascular Medicine. Philadelphia, WB Saunders, 1980, pp 1402-1403

18. Parker JO, et al: Effect of nitroglycerin ointment on the clinical and hemodynamic response to exercise. Am I Cardiol 38:162, 1976

19. Reichek $N$, et al: Sustained effects of nitroglycerin ointment in patients with angina pectoris. Circulation 50:348, 1974

20. Thadani U, Parker JO: Propranolol in angina pectoris: Duration of improved exercise tolerance and circulatory effects after acute oral administration. Am / Cardiol 44:118, 1979

21. Crawford $\mathrm{MH}$, et al: Combined propranolol and digoxin therapy in angina pectoris. Ann Intern Med 83:449, 1975

22. Frishman $W H$, et al: Aspirin therapy in angina pectoris: Effect on platelet aggregation, exercise tolerance, and electrocardiographic manifestations of ischemia. Am Heart J 92:3, 1976

23. Roth G), et al: Acetylation of prostaglandin synthetase by aspirin Proc Nat Acad Sci USA 72:3073, 1975

24. Moskowitz RM, et al: Nifedipine therapy for stable angina pectoris: Preliminary results of effects on angina frequency and treadmill exercise response. Am J Cardiol 44:811, 1979

25. Report of the Unstable Angina Pectoris Study Group: Unstable Angina Pectoris: National Cooperative Group to Compare Medical and Surgical Therapy. II. In-Hospital Experience and Initial Follow-up Results in Patients with One, Two, and Three Vessel Disease. Am J Cardiol 42:839, 1978

26. Oliva PB, et al: Coronary artery spasm in Prinzmetal angina: Documentation by coronary arteriography. $N$ Engl / Med 288:745, 1973

27. Antuman E, et al: Nefedipine therapy for coronary spasm: Collective clinical experience in the United States. Circulation 60 (suppl II):76, 1979

28. Selzer $A$, et al: Clinical syndrome of variant angina with normal coronary arteriogram. N Engl I Med 295:1343, 1976

29. Kannel WB, Feinleib $M$ : Natural history of angina pectoris in the Framingham study. Prognosis and survival. Am J Cardiol 29:154, 1972

\section{Venous Ulcers}

Venous ulcers characteristically arise within the gaiter skin above the ankle joint, developing in an area of skin and subcutaneous fat that has become thickened, inflamed, and pigmented. This abnormal state of the skin and subcutaneous tissue has been called fat necrosis, but the microscopic features of fat necrosis at other sites are different and the term lipodermatosclerosis has been coined to take account of the skin change and the histological appearance. Venous ulcers vary greatly in size but are usually oval or serpiginous in shape and often multiple. They are most commonly medial in position but may be lateral or even anteriorly placed and are usually centred within a hand's-breadth of the ankle joint. The edge of a venous ulcer is flat with sloping walls and any suggestion of punching out or eversion of the edge should raise the possibility that the ulcer is syphilitic or a squamous cell carcinoma. Large basal cell carcinomas sometimes cause diagnostic uncertainty when they occur around the ankle, and squamous cell carcinoma may develop in a longstanding venous ulcer. Any long delay in ulcer healing is therefore indication for biopsy. The base of the ulcer is usually flat and covered by a variable quantity of infected slough. When the ulcer starts to heal the slough is gradually shed, healthy vascular granulation tissue appears in the base, and a pale pink rim of new epithelium starts to grow in from the edge._Diagnosis and treatment of venous ulceration. Lancet ii:247, 1982 
This document is a scanned copy of a printed document. No warranty is given about the accuracy of the copy. Users should refer to the original published version of the material. 